\title{
Impactos da higiene bucal de pacientes em terapia intensiva sobre pneumonias nosocomiais e associadas à ventilação mecânica: revisão integrativa da literatura
}

Impacts of intensive care patients' oral hygiene on nosocomial and ventillator-associated pneumonia: integrative literature review

Impacto de la higiene bucal de los pacientes de cuidados intensivos en la neumonía nosocomial y asociada a la ventilación: revisión bibliográfica integradora

\author{
Gabriel Borges Di Paolo \\ ORCID: https://orcid.org/0000-0002-6019-0841 \\ Centro Universitário de Patos de Minas, Brasil \\ E-mail: gabrielborgesdipaolo@unipam.edu.br \\ Carolina Silva Pereira \\ ORCID: https://orcid.org/0000-0003-2020-3932 \\ Centro Universitário de Patos de Minas, Brasil \\ E-mail: carolinasp@unipam.edu.br \\ Anísio Rodiney Souza Júnior \\ ORCID: https://orcid.org/0000-0002-3750-6182 \\ Centro Universitário de Patos de Minas, Brasil \\ E-mail: anisiorsj@unipam.edu.br \\ Fabrício Campos Machado \\ ORCID: https://orcid.org/0000-0003-4603-8795 \\ Centro Universitário de Patos de Minas, Brasil \\ E-mail: fabriciocampos@unipam.edu.br \\ Thiago de Amorim Carvalho \\ ORCID: https://orcid.org/0000-0003-1153-0931 \\ Centro Universitário de Patos de Minas, Brasil \\ E-mail: thiagocarvalho@unipam.edu.br
}

\begin{abstract}
Resumo
A Odontologia Hospitalar tem ganhado campo, já que diversas experiências exitosas, associadas à evidências científicas tem demonstrado que a assistência odontológica a nível hospitalar pode contribuir para a redução dos casos de pneumonia nosocomial, associada à ventilação mecânica reduzindo assim o tempo de internação e consequentemente os custos desse processo. O objetivo desse trabalho foi verificar a eficácia dos protocolos de higienização bucal em pacientes internados em UTI, na prevenção da pneumonia associada à ventilação mecânica ou pneumonia nosocomial. Foi realizada uma revisão integrativa da literatura com buscas nas bases de dados Pubmed/MEDLINE e Scielo, na qual 23 artigos foram selecionados para a análise qualitativa após a aplicação dos critérios de elegibilidade norteados pela estratégia PRISMA. Percebe-se que o uso de Clorexidina parece ser o protocolo mais recorrente nos estudos, inclusive, com melhores resultados quando associado à adequação mecânica propiciada pela escovação, na redução dos casos de pneumonia nosocomial. Outros métodos como o uso da Iodopovidona e aspiração supraglótica foram citados, embora seus efeitos ainda sejam controversos. Dessa forma, conclui-se que apesar de não haver um protocolo bem delineado para o controle do biofilme oral e consequente redução da prevalência das pneumonias, a Clorexidina associada à escovação parece ser o método mais promissor. Mais estudos com metodologias robustas são necessários para a compreensão e propostas de protocolos baseados em evidências científicas para higienização oral de pacientes em terapia intensiva, com foco em reduzir a morbimortalidade por pneumonia nosocomial.
\end{abstract}

Palavras-chave: Equipe hospitalar de odontologia; Odontologia; Unidade de Terapia Intensiva; Higiene bucal.

\begin{abstract}
Hospital Dentistry has been gaining field, since several successful experiences, associated with scientific evidence have shown that dental care at the hospital level can contribute to the reduction of cases of nosocomial pneumonia associated with mechanical ventilation, thus reducing the length of hospital stay and consequently the costs of this process. The objective of this study was to verify the efficacy of oral hygiene protocols in ICU patients in the prevention of ventilator-associated pneumonia or nosocomial pneumonia. An integrative literature review was carried out with searches in the Pubmed/MEDLINE and Scielo databases, in which 23 articles were selected for qualitative analysis after application of the eligibility criteria guided by the PRISMA strategy. We noticed that the use of
\end{abstract}


chlorhexidine seems to be the most recurrent protocol in the studies, with better results when associated with the mechanical adequacy provided by brushing, in reducing the cases of nosocomial pneumonia. Other methods such as the use of povidone-iodine and supraglottic aspiration were mentioned, although their effects are still controversial. Thus, we conclude that although there is not a well-defined protocol for the control of oral biofilm and consequent reduction in the prevalence of pneumonia, chlorhexidine associated with brushing seems to be the most promising method. More studies with robust methodology are needed for the understanding and proposal of protocols based on scientific evidence for oral hygiene of patients in intensive care, focused on reducing morbidity and mortality from nosocomial pneumonia.

Keywords: Hospital dental staff; Dentistry; Intensive Care Unit; Oral hygiene.

\section{Resumen}

La Odontología Hospitalaria ha ido ganando terreno, ya que varias experiencias exitosas, asociadas a la evidencia científica han demostrado que la atención odontológica a nivel hospitalario puede contribuir a reducir los casos de neumonía nosocomial, asociada a la ventilación mecánica, reduciendo así la duración de la estancia hospitalaria y consecuentemente los costes de este proceso. El objetivo de este trabajo fue comprobar la eficacia de los protocolos de higiene oral en pacientes de la UCI en la prevención de la neumonía asociada al ventilador o la neumonía nosocomial. Se realizó una revisión bibliográfica integradora con búsquedas en las bases de datos Pubmed/MEDLINE y Scielo, en la que se seleccionaron 23 artículos para el análisis cualitativo tras la aplicación de los criterios de elegibilidad guiados por la estrategia PRISMA. Observamos que el uso de clorhexidina parece ser el protocolo más recurrente en los estudios, con mejores resultados cuando se asocia a la adecuación mecánica proporcionada por el cepillado, en la reducción de los casos de neumonía nosocomial. Se mencionaron otros métodos como la povidona yodada y la aspiración supraglótica, aunque sus efectos siguen siendo controvertidos. Así pues, concluimos que, aunque no existe un protocolo bien definido para el control del biofilm oral y la consiguiente reducción de la prevalencia de la neumonía, la clorhexidina asociada al cepillado parece ser el método más prometedor. Se necesitan más estudios con metodología robusta para conocer y proponer protocolos basados en la evidencia científica para la higiene bucal de los pacientes en cuidados intensivos, enfocados a reducir la morbilidad y mortalidad por neumonía nosocomial.

Palabras clave: Personal de odontología en hospital; Odontología; Unidades de Cuidados Intensivos; Higiene bucal.

\section{Introdução}

As Infecções Nosocomiais estão entre as principais causas de mortalidade em pacientes submetidos à ventilação mecânica (VM) em Unidade de Terapia Intensiva (UTI), pelo fato de a cavidade oral servir como um importante reservatório de patógenos respiratórios, aumentando o risco de se desenvolver a Pneumonia Nosocomial (PNC) (Haghighi et al., 2016).

O risco de se desenvolver a PNC aumenta com o uso da VM, fazendo que a doença se prolongue por mais dias, aumentando também os custos hospitalares. A contaminação de vias aéreas é oriunda de aspiração e inalação de bactérias presentes na cavidade oral, principalmente no biofilme dental (Santi \& Santos, 2016).

É necessário que se compreenda que cavidade oral e trato respiratório estão em íntimo contato, desta forma a colonização bacteriana da primeira refletirá diretamente sobre o segundo, e para pacientes que se encontram sedados, em unidade de terapia intensiva, sem reflexos protetores de tosse e em posição deitada, aumenta a susceptibilidade às infecções causadas pelos patógenos colonizadores. Dentre os patógenos comuns aos dois nichos e que mais são encontrados em análises de secreção pulmonar de pacientes intubados estão Pseudomonas aeruginosa, Staphylococcus aureus e Porphyromonas gingivalis que fazem parte do grupo de patógenos periodontais, considerados com a maior patogenicidade. Trata-se ainda de colonizadores tardios do biofilme, o que leva a crer que com a higiene bucal adequada, as chances dessas bactérias se desenvolverem no meio bucal diminui consideravelmente (Güler \& Türk, 2019; Jerônimo et al., 2020).

Em março de 2020 foi declarada pela Organização Mundial da Saúde (OMS) como pandemia a doença COVID-19, causada pelo vírus Sars-Cov-2. O primeiro caso foi diagnosticado em Wuhan, província chinesa, em dezembro de 2019 e sua manifestação apresenta-se como quadros respiratórios mais leves e assintomáticos até casos mais graves, podendo evoluir com a necessidade de intubação na UTI (Santos et al., 2020). Atualmente o número de mortes ultrapassa a quantidade de 4 milhões e 700 mil mundialmente, enquanto os casos confirmados ultrapassam 232 milhões.

Com alta transmissibilidade, esse vírus vem sendo uma grave ameaça à saúde humana e sua disseminação é através de contato próximo, gotículas salivares expelidas através de tosse e espirros, além de contato com objetos ou superfícies 
contaminadas, sendo os sintomas mais comuns febre, tosse e dificuldade para respirar (WHO, 2020; CDC et al., 2020). Pode agravar doenças pulmonares pela alteração da microbiota bucal aumentando sua patogenicidade e o seu controle está associado a possibilidade de co-infecções por SARS-CoV-2 nos pulmões (CFO, 2021).

Visando a redução do agravamento dessa doença a odontologia hospitalar vem ganhando mais destaque nesse momento. Definida como habilitação odontológica pela resolução 162/2015 (CFO, 2015), a odontologia hospitalar por meio do atendimento no leito deveria ser oferecida a todo paciente crítico que apresente alguma necessidade em suas estruturas bucais e anexos. Com um cuidado integral e multidisciplinar esse atendimento precisa ser discutido com a equipe assistencial (Bao et al, 2020; CFO, 2021).

É fundamental manter uma interação entre a odontologia com a equipe multidisciplinar, seja por meio ações de educação permanente e continuada, além de assistência clínica, proporcionando melhor assistência aos pacientes em uso de VM, minimizando o risco de disseminação de patógenos bucais, que podem causar complicações sistêmicas, estabelecendo medidas preventivas e facilitando o relacionamento entre os profissionais (Alecrim et al, 2019; Keyt, Faverio \& Restrepo, 2014).

Diversos estudos foram feitos em busca de definir um protocolo ideal de higiene bucal eficaz para a redução da incidência de Pneumonia associada à ventilação mecânica (PAVM). Dessa forma o objetivo deste trabalho é verificar a eficácia dos protocolos de higienização bucal em pacientes internados em UTI, na prevenção da pneumonia associada à ventilação mecânica ou pneumonia nosocomial.

\section{Metodologia}

Foi realizada uma revisão integrativa da literatura sobre o tema higiene bucal em pacientes em UTI e prevenção dos casos de pneumonia nosocomial e pneumonia associada a ventilação mecânica (PAVM).

Para tal revisão utilizou-se as seguintes palavras chave: pneumonia, saúde bucal, biofilme dental, unidade de terapia intensiva e seus correspondentes em inglês (pneumonia, oral health, dental biofilm, intensive care unit), nas bases de dados PUBMED/MEDLINE e Scielo, aplicando-se os critérios de inclusão: artigos em inglês e português, na integra,de até dez anos de publicação, metanálises, revisões sistemáticas e ensaios clínicos randomizados; e os critérios de exclusão: os artigos com mais de dez anos de publicação, idioma diverso ao estabelecido, artigos sem a possibilidade de localização do texto completo e gratuito, opiniões de especialistas, teses e dissertações. Na seleção dos artigos, foram utilizados os critérios de elegibilidade sugeridos pela estratégia PRISMA-Scr (Figura 1), a qual também serviu de base para a estruturação dessa revisão (Mendes et al., 2008).

A pergunta do estudo, elaborada pela estratégia PICO na qual P foram as pessoas internadas em terapia intensiva, para I foram atribuídos os protocolos de higienização da cavidade oral, o grupo controle (C) foram os pacientes que não recebem higiene bucal e os desfechos protocolos de higiene bucal; eficácia dos protocolos de higienização oral; controle do biofilme dental; impactos da higiene bucal sobre os casos de pneumonia nosocomial, desta maneira pergunta elaborada foi: Qual a eficácia dos protocolos de higienização da cavidade oral para o controle do biofilme e a prevenção da Pneumonia Nosocomial em pessoas internadas em terapia intensiva?" 
Figura 1 - Fluxograma do processo de seleção dos estudos primários adaptado do Preferred Reporting Items for Systematic review and Meta-Analyses (PRISMA ScR).

Identificação

Filtro: 10 anos

Tipos de estudo

conforme critérios de

inclusão

Textos completos
Elegibilidade

Inclusão

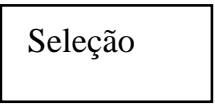$$
\text { Inclusão }
$$

Registro identificado no banco de dados de busca (Pubmed (pneumonia) AND (oral health)) AND (dental biofilm)) AND (intensive care unit) $-\mathrm{n}=3$

(pneumonia) AND (oral health)) AND (intensive care unit) $\mathrm{n}=281$ com filtros iniciais $\mathrm{n}=57$ )

Scielo $(\mathrm{n}=0)$

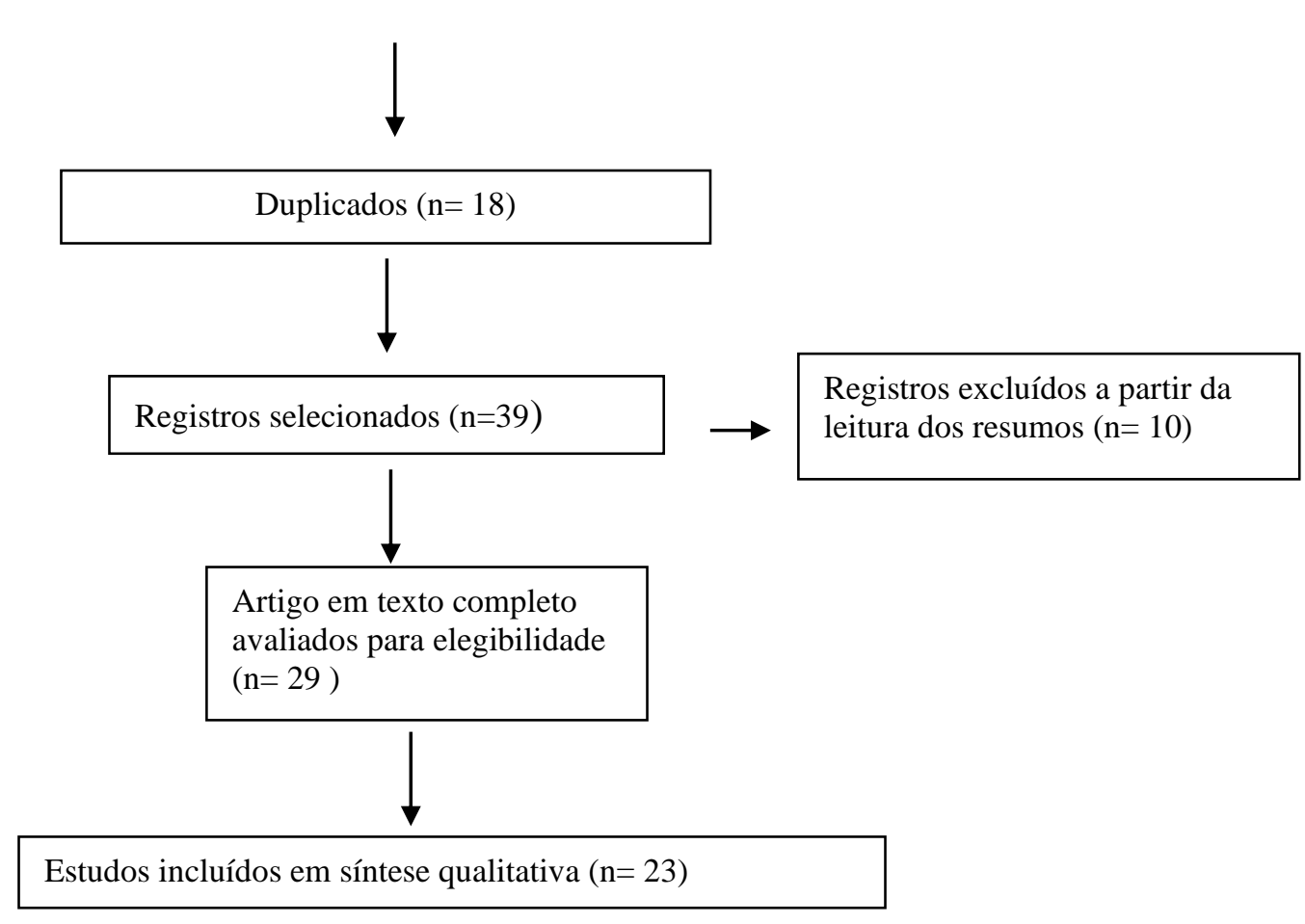

Fonte: Autores.

A partir da aplicação dos critérios de inclusão e exclusão foram selecionados 23 artigos a partir dos 281 que foram identificados na busca primária. Para tal seleção foram aplicados filtros relativos a tempo de publicação, duplicação da publicação, disponibilidade de texto completo e resposta aos desfechos da pergunta do estudo.

\section{Resultados}

Com base nos 23 estudos selecionados, pode-se destacar que a Clorexidina continua sendo o protocolo mais utilizado, cuja eficácia foi apresentada em 13 estudos. O uso do Iodopovidona como alternativo à clorexidina, foi abordado em apenas 3 estudos, sendo que em dois deles apresentou eficácia. A drenagem de secreções subglóticas e os cuidados com higiene bucal apresentaram bons resultados, sendo considerados protocolos em quase todos os estudos. A caracterização dos artigos por autor, ano de publicação, periódico, objetivo do trabalho, tipo de estudo e principais resultados estão descritos no Quadro 1. 
Quadro 1. Caracterização dos estudos selecionados conforme aplicação dos critérios de elegibilidade.

\begin{tabular}{|c|c|c|c|c|}
\hline $\begin{array}{l}\text { Autor e ano } \\
\text { de } \\
\text { publicação }\end{array}$ & Periódico & Objetivo & $\begin{array}{l}\text { Tipo de } \\
\text { estudo }\end{array}$ & Resultados \\
\hline $\begin{array}{l}\text { (1) Klompas, } \\
2019\end{array}$ & $\begin{array}{l}\text { Seminars in } \\
\text { Respiratory and } \\
\text { Critical Care } \\
\text { Medicine }\end{array}$ & $\begin{array}{c}\text { Revisar estudos recentes para } \\
\text { compreender quais os melhores } \\
\text { métodos de prevenção da pneumonia } \\
\text { adquirida na UTI. }\end{array}$ & $\begin{array}{l}\text { Revisão } \\
\text { Sistemática }\end{array}$ & $\begin{array}{l}\text { Os estudos indicaram que a elevação do } \\
\text { leito não interfere consideravelmente, assim } \\
\text { como, a drenagem de secreção subglótica } \\
\text { não apresentou nenhum impacto na duração } \\
\text { de internação ou mortalidade. Cuidados } \\
\text { bucais com clorexidina tem efeito limitado e } \\
\text { pode aumentar as taxas de mortalidade. } \\
\text { Escovação seletiva continua sendo a única } \\
\text { estratégia associada à menores taxas de } \\
\text { mortalidade. }\end{array}$ \\
\hline $\begin{array}{l}\text { (2) Hua et } \\
\text { al., } 2016\end{array}$ & $\begin{array}{l}\text { Cochrane Database } \\
\text { of Systematic } \\
\text { Reviews }\end{array}$ & $\begin{array}{l}\text { Avaliar os efeitos dos cuidados de } \\
\text { higiene oral na incidência de ventilação } \\
\text { associada a pneumonia em pacientes } \\
\text { que estejam recebendo ventilação } \\
\text { mecânica em UTI. }\end{array}$ & $\begin{array}{l}\text { Revisão } \\
\text { sistemática }\end{array}$ & $\begin{array}{l}\text { Cuidados de higiene bucal incluindo } \\
\text { colutório com clorexidina reduz o risco de } \\
\text { desenvolver pneumonia associada à } \\
\text { ventilação mecânica de } 24 \% \text { a cerca de } \\
18 \% \text {. Não parece haver influência dos tipos } \\
\text { de escova (manual ou elétrica) sobre a } \\
\text { redução os casos de pneumonia. }\end{array}$ \\
\hline $\begin{array}{l}\text { (3) Rabello, } \\
\text { Araújo \& } \\
\text { Magalhães, } \\
2018\end{array}$ & $\begin{array}{c}\text { International } \\
\text { Journal of Dental } \\
\text { Hygiene }\end{array}$ & $\begin{array}{c}\text { Resumir as evidências sobre a eficácia } \\
\text { do uso de clorexidina para saúde bucal } \\
\text { em pacientes de UTI, para prevenção da } \\
\text { Pneumonia Nosocomial (PN) e } \\
\text { pneumonia associada à ventilação. }\end{array}$ & $\begin{array}{l}\text { Pesquisa } \\
\text { Exploratória, } \\
\text { Revisão. }\end{array}$ & $\begin{array}{l}\text { Os resultados do estudo demonstraram que a } \\
\text { clorexidina } 0,12 \% \text { tem se mostrado eficaz } \\
\text { na prevenção da PN em pacientes adultos. }\end{array}$ \\
\hline $\begin{array}{l}\text { (4) Haghighi } \\
\text { et al., } 2016\end{array}$ & $\begin{array}{c}\text { Australian Critical } \\
\text { Care }\end{array}$ & $\begin{array}{c}\text { Identificar o impacto das práticas de } \\
\text { higiene bucal na saúde bucal de pacientes } \\
\text { em unidade de terapia intensiva e a taxa } \\
\text { de incidência de pneumonia associada à } \\
\text { ventilação mecânica. }\end{array}$ & $\begin{array}{l}\text { Estudo caso } \\
\text { controle }\end{array}$ & $\begin{array}{l}\text { Os resultados obtidos demonstram que não } \\
\text { houve diferença estatisticamente significativa } \\
\text { entre os grupos que utilizaram solução salina } \\
0,9 \% \text {, clorexidina } 0,2 \% \text { e escovação } \\
\text { mecânica, para os casos de pneumonia, } \\
\text { embora os grupos que sofreram intervenção } \\
\text { apresentaram melhora significativa na saúde } \\
\text { bucal e índice de placa. }\end{array}$ \\
\hline $\begin{array}{l}\text { (5) Alecrim et } \\
\text { al., } 2019\end{array}$ & $\begin{array}{l}\text { Revista Brasileira } \\
\text { de Enfermagem }\end{array}$ & $\begin{array}{l}\text { Identificar estudos acerca de estratégias } \\
\text { de prevenção de pneumonia associada à } \\
\text { ventilação mecânica implantadas em } \\
\text { serviços de saúde e classificar o nível de } \\
\text { evidência destes }\end{array}$ & $\begin{array}{l}\text { Revisão de } \\
\text { escopo }\end{array}$ & $\begin{array}{c}\text { Dentre as propostas de cada estudo, foram } \\
\text { destaques o decúbito elevado de } 30^{\circ} \text { a } 45^{\circ} \text {, } \\
\text { higiene oral com clorexidina, e desmame da } \\
\text { sedação sempre que possível ou despertar } \\
\text { diário da sedação. } \\
\text { A maioria dos estudos incluídos, relatam a } \\
\text { importância dos profissionais de saúde } \\
\text { conhecerem as taxas de PAV de seus } \\
\text { serviços, receberem orientações e feedback } \\
\text { sobre a conformidade das medidas que } \\
\text { previnem a PAV e manterem vigilância } \\
\text { contínua }\end{array}$ \\
\hline $\begin{array}{l}\text { (6) Güler \& } \\
\text { Türk, } 2019\end{array}$ & $\begin{array}{l}\text { Western Journal of } \\
\text { Nursing Research }\end{array}$ & $\begin{array}{l}\text { Determinar o efeito da clorexidina em } \\
\text { diferentes concentrações e frequências na } \\
\text { pneumonia associada a ventilação e } \\
\text { colonização microbiana em pacientes } \\
\text { ventilados mecanicamente. }\end{array}$ & $\begin{array}{l}\text { Estudo caso } \\
\text { controle }\end{array}$ & $\begin{array}{l}\text { A clorexidina é uma intervenção eficaz na } \\
\text { higiene bucal do ventilador pneumonia } \\
\text { associada e colonização microbiana. Os } \\
\text { resultados demonstraram que a clorexidina } \\
0,2 \% \text { foi considerada mais eficaz do que o } \\
\text { grupo controle na prevenção e } \\
\text { desenvolvimento de pneumonia associada a } \\
\text { ventilação. A aplicação duas vezes ao dia foi } \\
\text { considerada eficaz na redução da taxa de } \\
\text { pneumonia associada à ventilação usando } \\
0,2 \% \text { e } 2 \% \text { clorexidina. A colonização } \\
\text { microbiana foi menor no grupo de } \\
\text { clorexidina } 2 \% \text { do que no grupo que utilizou } \\
\text { enxaguatório bucal à base de ervas } 0,9 \% \text { e } \\
\text { clorexidina } 0,2 \% \text {. }\end{array}$ \\
\hline $\begin{array}{l}\text { (7) Collina et } \\
\text { al., } 2017\end{array}$ & TRIALS BMC & $\begin{array}{l}\text { Avaliar o uso do Azul Metileno e } \\
\text { Terapia Fotodinâmica em formula de } \\
\text { enxaguatante bucal na prevenção de } \\
\text { infecções nosocomiais. }\end{array}$ & $\begin{array}{l}\text { Estudo clínico } \\
\text { randomizado }\end{array}$ & $\begin{array}{l}\text { Fase 1: o principal desfecho será a eficácia } \\
\text { dos procedimentos de higiene bucal, avaliada } \\
\text { pela contagem total de bactérias, antes e após } \\
\text { os tratamentos (três grupos e dois } \\
\text { momentos). Um resultado secundário que } \\
\text { pode ser medido é a mudança na contagem }\end{array}$ \\
\hline
\end{tabular}




\begin{tabular}{|c|c|c|c|c|}
\hline & & & & $\begin{array}{c}\text { de bactérias patogênicas que está relacionada } \\
\text { à PAV após os procedimentos de higiene } \\
\text { bucal. } \\
\text { Fase 2: o desfecho principal será a taxa de } \\
\text { PAV, avaliada por meio da checagem dos } \\
\text { prontuários, } 5 \text { dias após os procedimentos } \\
\text { diários de higiene bucal. } \\
\text { Chegou-se a conclusão que ao considerar a } \\
\text { resistência de microrganismos a muitos } \\
\text { antimicrobianos diferentes [69], o PDT } \\
\text { parece ser uma ferramenta interessante, uma } \\
\text { vez que pode ser considerada eficaz, } \\
\text { independente da resistência do } \\
\text { microrganismo }\end{array}$ \\
\hline $\begin{array}{l}\text { (8) Guerra et } \\
\text { al., } 2016\end{array}$ & $\begin{array}{l}\text { La Clinica } \\
\text { Terapeutica }\end{array}$ & $\begin{array}{l}\text { Fornecer uma narrativa atualizada e uma } \\
\text { revisão sistemática para demonstrar } \\
\text { ainda mais como a higiene oral adequada } \\
\text { é crítica para reduzir o risco de } \\
\text { desenvolver PAV em pacientes } \\
\text { criticamente enfermos. }\end{array}$ & $\begin{array}{l}\text { Revisão } \\
\text { Sistemática }\end{array}$ & $\begin{array}{l}\text { Os resultados deste estudo sugerem que o uso } \\
\text { de antimicrobianos combinados com a } \\
\text { escovação dos dentes pode contribuir } \\
\text { ativamente para reduzir a incidência de PAV. }\end{array}$ \\
\hline $\begin{array}{l}\text { (9) Lacerda } \\
\text { Vidal et al., } \\
2017\end{array}$ & $\begin{array}{c}\text { BMC INFECTIOUS } \\
\text { DISEASES }\end{array}$ & $\begin{array}{l}\text { Verificar se a higiene oral por meio de } \\
\text { escovação dentária mais clorexidina em } \\
\text { gel a } 0,12 \% \text { reduz a incidência de } \\
\text { pneumonia associada à ventilação } \\
\text { mecânica, o tempo de internação } \\
\text { hospitalar e a taxa de mortalidade em } \\
\text { UTIs, quando comparada à higiene bucal } \\
\text { apenas com clorexidina, solução } 0,12 \%, \\
\text { sem escovação dentária, em indivíduos } \\
\text { adultos em ventilação mecânica, } \\
\text { internados em Unidades de Terapia } \\
\text { Intensiva (UTI) Clínica / Cirúrgica e } \\
\text { Cardiologia. }\end{array}$ & $\begin{array}{c}\text { Pesquisa } \\
\text { Exploratória }\end{array}$ & $\begin{array}{l}\text { A escovação dentária associada a gel de } \\
\text { clorexidina } 0,12 \% \text { demonstrou menor } \\
\text { incidência de PAV ao longo do período de } \\
\text { acompanhamento, embora a diferença não } \\
\text { tenha sido estatisticamente significativa (p }= \\
0,084) \text {. Houve redução significativa do tempo } \\
\text { médio de ventilação mecânica no grupo } \\
\text { escovação ( } \mathrm{p}=0,018) \text {. Em relação ao tempo } \\
\text { de internação na UTI e taxas de mortalidade, } \\
\text { a diferença não foi estatisticamente } \\
\text { significativa }(\mathrm{p}=0,064) \text {. }\end{array}$ \\
\hline $\begin{array}{l}\text { (10) Zhao et } \\
\text { al., } 2020\end{array}$ & Cochrane Library & $\begin{array}{l}\text { Avaliar os efeitos do OHC na incidência } \\
\text { de PAV em pacientes críticos em } \\
\text { ventilação mecânica em unidades de } \\
\text { terapia intensiva (UTIs) de hospitais. }\end{array}$ & $\begin{array}{l}\text { Revisão } \\
\text { sistemática }\end{array}$ & $\begin{array}{l}\text { OHC é importante para pacientes ventilados } \\
\text { em terapia intensiva. O OHC que inclui } \\
\text { enxaguatório bucal com clorexidina ou gel } \\
\text { está associado a uma redução de } 40 \% \text { nas } \\
\text { chances de desenvolver pneumonia associada } \\
\text { à ventilação em adultos gravemente } \\
\text { enfermos. No entanto, não há evidência de } \\
\text { diferença nos resultados de mortalidade, } \\
\text { duração da ventilação mecânica ou tempo de } \\
\text { permanência na UTI. Não há evidências de } \\
\text { que OHC incluindo CHX e escovação } \\
\text { dentária seja diferente de OHC com CHX } \\
\text { sozinho, e algumas evidências fracas } \\
\text { sugerem que o enxaguatório bucal com iodo } \\
\text { povidona é mais eficaz do que solução salina } \\
\text { na redução da PAV. Não há evidências } \\
\text { suficientes para determinar se a escovação } \\
\text { elétrica ou outras soluções de higiene bucal } \\
\text { são eficazes na redução da PAVM }\end{array}$ \\
\hline $\begin{array}{l}\text { (11) Keyt, } \\
\text { Faverio \& } \\
\text { Restrepo, } \\
\quad 2014\end{array}$ & $\begin{array}{l}\text { Indian Journal of } \\
\text { Medical Research }\end{array}$ & $\begin{array}{l}\text { Revisar a literatura recente relativa a } \\
\text { estratégias de prevenção de PAV } \\
\text { baseadas em evidências que resultaram } \\
\text { em resultados clinicamente. }\end{array}$ & $\begin{array}{l}\text { Revisão da } \\
\text { literatura }\end{array}$ & $\begin{array}{l}\text { A PAV continua a ser um desafio comumente } \\
\text { encontrado entre os pacientes criticamente } \\
\text { enfermos e traz consigo uma carga } \\
\text { significativa de morbidade, utilização de } \\
\text { antibióticos e custo. Estudos sobre estratégias } \\
\text { de prevenção direcionadas aos mecanismos } \\
\text { fisiopatológicos da PAV têm mostrado } \\
\text { sucesso variável. }\end{array}$ \\
\hline $\begin{array}{l}\text { (12) El- } \\
\text { Rabbany et } \\
\text { al., } 2015\end{array}$ & $\begin{array}{c}\text { International Journal } \\
\text { of Nursing Studies }\end{array}$ & $\begin{array}{l}\text { Identificar várias doenças bucais, } \\
\text { procedimentos realizados em unidade de } \\
\text { terapia intensiva ou ambiente de lar de } \\
\text { idosos, para ajudar na redução de } \\
\text { incidência de pneumonia adquirida em } \\
\text { hospital e associada à ventilação } \\
\text { mecânica. }\end{array}$ & $\begin{array}{l}\text { Revisão } \\
\text { sistemática }\end{array}$ & $\begin{array}{l}\text { Concluíram que os cuidados de saúde bucal } \\
\text { estejam indicando uma redução do risco em } \\
\text { adquirir a pneumonia hospitalar e a } \\
\text { pneumonia associada à ventilação mecânica } \\
\text { em pacientes de alto risco. Além disso,por } \\
\text { meio da revisão de estudos que avaliam a } \\
\text { eficácia da clorexidina, descobriram que, } \\
\text { apesar da presença de resultados mistos, essa } \\
\text { clorexidina pode ser um método }\end{array}$ \\
\hline
\end{tabular}




\begin{tabular}{|c|c|c|c|c|}
\hline & & & & $\begin{array}{l}\text { particularmente eficaz em reduzir o risco de } \\
\text { pneumonia hospitalar e associada à } \\
\text { ventilação mecânica. }\end{array}$ \\
\hline $\begin{array}{l}\text { (13) Takeyasu } \\
\text { et al., } 2014\end{array}$ & $\begin{array}{l}\text { Bull Tokyo Dent } \\
\text { Coll }\end{array}$ & $\begin{array}{l}\text { Investigar a relação entre a PAV e vários } \\
\text { métodos de cuidados com a saúde bucal. }\end{array}$ & $\begin{array}{l}\text { Estudo clínico } \\
\text { randomizado }\end{array}$ & $\begin{array}{l}\text { Em comparações entre os dois grupos, houve } \\
\text { diferenças significativas em contaminação no } \\
\text { manguito, em relação a níveis de cuidados de } \\
\text { saúde oral e em tempo de intubação. Não } \\
\text { houve diferenças significativas relacionados } \\
\text { ao sexo, idade, número de remanescentes } \\
\text { dentários, ou presença ou ausência de febre. } \\
\text { Nenhum PAVM ocorreu em nenhum dos } \\
\text { grupos durante o período de estudo. }\end{array}$ \\
\hline $\begin{array}{l}\text { (14) Lee et al., } \\
2019\end{array}$ & Respiratory Care & $\begin{array}{l}\text { Explorar a taxa de mortalidade } \\
\text { relacionada à clorexidina para indivíduos } \\
\text { em ventilação mecânica em uma UTI, } \\
\text { quando comparados com indivíduos que } \\
\text { receberam cuidados de UTI padrão. }\end{array}$ & $\begin{array}{l}\text { Revisão } \\
\text { Sistemática }\end{array}$ & $\begin{array}{l}\text { No geral, evidências de qualidade moderada } \\
\text { indicaram incidência reduzida de pneumonia } \\
\text { associada à ventilação, sem um efeito } \\
\text { substancial na taxa de mortalidade. A } \\
\text { administração profilática de clorexidina entre } \\
\text { pacientes criticamente enfermos e em UTI } \\
\text { reduziu a ocorrência de pneumonia associada } \\
\text { à ventilação mecânica, sem impacto } \\
\text { significativo na mortalidade associada. }\end{array}$ \\
\hline $\begin{array}{l}\text { (15) Jerônimo } \\
\text { et al., } 2020\end{array}$ & $\begin{array}{c}\text { Oral Health and } \\
\text { Preventive Dentistry }\end{array}$ & $\begin{array}{l}\text { Avaliar a relação entre periodontite e } \\
\text { pneumonia nosocomial em unidade de } \\
\text { terapia intensiva (UTI)pacientes. }\end{array}$ & $\begin{array}{l}\text { Revisão } \\
\text { Sistemática } \\
\text { com } \\
\text { Metanálise }\end{array}$ & $\begin{array}{l}\text { Houve uma associação significativa entre } \\
\text { periodontite e pneumonia nosocomial na } \\
\text { meta-análise }\end{array}$ \\
\hline $\begin{array}{l}\text { (16) Tsuda et } \\
\text { al., } 2020\end{array}$ & BMC Oral Health. & $\begin{array}{l}\text { Investigar se iodopovidona tópica inibe o } \\
\text { crescimento bacteriano e perturba o } \\
\text { equilíbrio da microbiota oral. }\end{array}$ & $\begin{array}{l}\text { Estudo caso- } \\
\text { controle }\end{array}$ & $\begin{array}{l}\text { Após a irrigação da cavidade oral, o número } \\
\text { de bactérias diminuiu, mas aumentou } \\
\text { novamente } 1 \mathrm{~h} \text { após o cuidado bucal no } \\
\text { grupo controle; entretanto, no grupo de } \\
\text { intervenção, a concentração de bactérias foi } \\
\text { significativamente menor do que no grupo } \\
\text { controle em } 1 \text { hora }(\mathrm{p}=0,009), 2 \text { horas ( } \mathrm{p} \\
=0,001) \text { e } 3 \text { horas }(\mathrm{p}=0,001) \text { após a } \\
\text { higiene bucal. O crescimento de todas as } \\
\text { espécies bacterianas testadas foi inibido no } \\
\text { grupo de intervenção } 3 \text { h após a higiene oral, } \\
\text { sugerindo que iodopovidona não perturbou o } \\
\text { equilíbrio da microbiota oral. }\end{array}$ \\
\hline $\begin{array}{l}\text { (17) Mccue \& } \\
\text { Palmer, } 2019\end{array}$ & J Nurs Care Qua & $\begin{array}{c}\text { Explorar o uso da solução de } \\
\text { descontaminação oral clorexidina (CHX) } \\
\text { para reduzir a pneumonia associada ao } \\
\text { ventilador (PAVM) em um ambiente de } \\
\text { manutenção do ventilador de longo prazo } \\
\text { ao longo do tempo. }\end{array}$ & $\begin{array}{l}\text { Pesquisa } \\
\text { Exploratória e } \\
\text { transversal }\end{array}$ & $\begin{array}{c}\text { Embora o tamanho da amostra fosse } \\
\text { pequeno, muitos dos veteranos em } \\
\text { ventiladores usaram CHX por anos sem um } \\
\text { incidente de PAVM. Esses achados apóiam o } \\
\text { uso de CHX para reduzir significativamente } \\
\text { o número de dias de administração } \\
\text { intravenosa antibióticos usados para tratar a } \\
\text { PAV com poucos efeitos colaterais }\end{array}$ \\
\hline $\begin{array}{l}\text { (18) Yao et } \\
\text { al., } 2011\end{array}$ & $\begin{array}{l}\text { The Journal de } \\
\text { Nursing Research }\end{array}$ & $\begin{array}{c}\text { Avaliar os efeitos de escovação dos } \\
\text { dentes duas vezes ao dia com água } \\
\text { purificada em pacientes pós- } \\
\text { neurocirúrgicos em unidade de terapia } \\
\text { intensiva, observado as taxas de PAVM. }\end{array}$ & $\begin{array}{l}\text { Pesquisa } \\
\text { transversal, } \\
\text { exploratória }\end{array}$ & $\begin{array}{l}\text { Os pacientes }(\mathrm{N}=53 \text { ) eram } \\
\text { predominantemente do sexo masculino } \\
(64,2 \%) \text {, a média de idade foi de } 60,6 \text { anos e } \\
\text { a maioria havia realizado cirurgia de urgência } \\
(75,5 \%) \text {. Após } 7 \text { dias de escovação com água } \\
\text { purificada, as taxas cumulativas de PAV } \\
\text { foram significativamente menores no grupo } \\
\text { experimental }(17 \%) \text { do que no grupo controle } \\
(71 \% ; \mathrm{p}<0,05) \text {. O grupo experimental } \\
\text { também teve escores significativamente } \\
\text { melhores para saúde bucal ( } \mathrm{p}<0,05) \text { e índice } \\
\text { de placa ( } \mathrm{p}<0,01) \text {. Os resultados sugerem } \\
\text { que, como uma alternativa barata aos } \\
\text { protocolos existentes, escovar os dentes duas } \\
\text { vezes ao dia com água purificada reduz a } \\
\text { PAVM e melhora a saúde e higiene bucal. }\end{array}$ \\
\hline $\begin{array}{l}\text { (19) Silvestri } \\
\text { et al., } 2016\end{array}$ & $\begin{array}{c}\text { Journal of } \\
\text { Cardiothoracic and } \\
\text { Vascular Anesthesia }\end{array}$ & $\begin{array}{l}\text { Avaliar o efeito da clorexidina sobre a } \\
\text { incidência de infecção da corrente } \\
\text { sanguínea, o microrganismo causador e } \\
\text { na mortalidade por todas as causas em } \\
\text { pacientes gravemente enfermos }\end{array}$ & $\begin{array}{l}\text { Revisão } \\
\text { sistemática } \\
\text { com meta- } \\
\text { análise }\end{array}$ & $\begin{array}{l}\text { Esta revisão sistemática mostrou que a } \\
\text { higiene oral com clorexidina não reduziu a } \\
\text { incidência de infecções em corrente } \\
\text { sanguínea e mortalidade. }\end{array}$ \\
\hline
\end{tabular}




\begin{tabular}{|c|c|c|c|c|}
\hline $\begin{array}{l}\text { (20) Zhang, } \\
\text { Tang \& Fu, } \\
2013\end{array}$ & $\begin{array}{c}\text { Journal of Clinical } \\
\text { Nursing }\end{array}$ & $\begin{array}{l}\text { Avaliar a eficácia da clorexidina para a } \\
\text { prevenção de pneumonia associada à } \\
\text { ventilação mecânica e explorar a } \\
\text { concentração ideal de clorexidina. }\end{array}$ & $\begin{array}{l}\text { Revisão } \\
\text { Sistemática } \\
\text { com Meta- } \\
\text { Análise }\end{array}$ & $\begin{array}{l}\text { Dezoito ensaios clínicos randomizados foram } \\
\text { incluídos e uma meta-análise foi usada. } \\
\text { Todos os estudos indicaram que a clorexidina } \\
\text { poderia prevenir e reduzir significativamente } \\
\text { a incidência de pneumonia associada ao } \\
\text { ventilador [RR }=0459 \text {, IC de } 95 \%(0450- \\
\text { 0469), p <0400001]. Nove estudos } \\
\text { mostraram } 41,2 \% \text { de clorexidina teve um } \\
\text { efeito significativo [RR = 0453, 95\% CI } \\
\text { (0443-0467),p <0400001]. Três estudos } \\
\text { comprovaram o efeito da clorexidina } 2 \% \text { na } \\
\text { prevenção da pneumonia associada à } \\
\text { ventilação mecânica }[R R=0455, \text { IC de } 95 \% \\
\text { (0437-0481), p = 04002] }\end{array}$ \\
\hline $\begin{array}{l}(21) \\
\text { Bellissimo- } \\
\text { Rodrigues et } \\
\text { al., } \\
2014\end{array}$ & $\begin{array}{l}\text { infection control } \\
\text { and hospital } \\
\text { epidemiology }\end{array}$ & $\begin{array}{l}\text { Avaliar se o tratamento odontológico } \\
\text { pode melhorar a antissepsia oral, } \\
\text { evitando assim de forma mais eficaz } \\
\text { infecções do trato respiratório inferior } \\
\text { entre pacientes criticamente enfermos. }\end{array}$ & $\begin{array}{c}\text { Estudo } \\
\text { transversal e } \\
\text { exploratório }\end{array}$ & $\begin{array}{l}\text { O tratamento odontológico foi seguro e } \\
\text { eficaz na prevenção de infecções do trato } \\
\text { respiratório inferior entre pacientes } \\
\text { gravemente enfermos que deveriam } \\
\text { permanecer pelo menos } 48 \text { horas na UTI. }\end{array}$ \\
\hline $\begin{array}{l}\text { (22) Viana et } \\
\text { al., } 2013\end{array}$ & $\begin{array}{l}\text { International Journal } \\
\text { for Quality in } \\
\text { Health Care }\end{array}$ & $\begin{array}{c}\text { O objetivo do estudo foi avaliar a } \\
\text { redução das taxas de incidência de } \\
\text { pneumonia associada à ventilação (PAV) } \\
\text { por meio de um programa de prevenção } \\
\text { racional. }\end{array}$ & $\begin{array}{c}\text { Pesquisa } \\
\text { Exploratória e } \\
\text { transversal }\end{array}$ & $\begin{array}{l}\text { A taxa média observada antes da intervenção } \\
\text { foi de 18,6 } \pm 7,8 \text { / } 1000 \text { dias-ventilação (IC } \\
95 \% \text { 8,7-14,9), diminuindo para } 11,8 \pm 7,8 \text { / } \\
1000 \text { dias-ventilação (IC } 95 \% 15,5-21,7 \text { ) ( P } \\
\text { = 0,002) após as intervenções. }\end{array}$ \\
\hline $\begin{array}{l}(23) \\
\text { Hayashida et } \\
\text { al., } 2016\end{array}$ & BMC Oral Health & $\begin{array}{l}\text { O objetivo deste estudo foi examinar os } \\
\text { efeitos de vários métodos de higiene } \\
\text { bucal na redução de bactérias orais } \\
\text { durante a intubação. }\end{array}$ & $\begin{array}{c}\text { Pesquisa } \\
\text { Transversal } \\
\text { Exploratória }\end{array}$ & $\begin{array}{l}\text { O cuidado oral com a escovação dos dentes e } \\
\text { limpeza da mucosa não reduziu as bactérias } \\
\text { orais, enquanto a irrigação da cavidade oral e } \\
\text { orofaringe diminuiu significativamente para } \\
\text { um nível de } 10 \text { (5) ufc / } \mathrm{mL} \text { ( } \mathrm{p}<0,001 \text { ). No } \\
\text { entanto, as bactérias orais aumentaram } \\
\text { novamente para quase } 10 \text { (8) ufc / mL dentro } \\
\text { de três horas de irrigação. As bactérias orais } \\
\text { não diminuíram com a aplicação tópica de } \\
\text { iodopovidona. Em contraste, } 30 \text { min após a } \\
\text { administração tópica de tetraciclina, o } \\
\text { número de bactérias orais diminuiu para } 10 \\
\text { (5) ufc / mL e permaneceu abaixo de } 10 \text { (6) } \\
\text { ufc / mL durante todo o período experimental } \\
\text { de } 150 \text { min. A irrigação da cavidade oral e } \\
\text { orofaringe seguida pela administração de } \\
\text { antibióticos tópicos pode reduzir as bactérias } \\
\text { orais em pacientes ventilados } \\
\text { mecanicamente. }\end{array}$ \\
\hline
\end{tabular}

Fonte: Autores.

Foram abordados 23 artigos, sendo: $26 \%$ revisões sistemáticas (6); 8,6\% pesquisas exploratórias (2); 13\% estudos de casos controle (3); 4,3\% revisão de escopo (1); 8,6 \% estudos clínicos randomizados (2); 4,6\% revisão de literatura (1); $13 \%$ revisões sistemáticas com metanálises (3) e 21,7\% pesquisas exploratórias e transversais (5). Os estudos que tiveram maior relevância para este trabalho foram as revisões sistemáticas, estudos clínicos randomizados e as pesquisas exploratórias.

\section{Discussão}

De acordo com Hua et al (2016) e Collina et al (2017) quando o paciente se encontra em uma UTI, o biofilme oral e a saburra lingual aumentam simultaneamente ao passar dos dias. Devido à intubação orotraqueal, a boca fica aberta durante todo o período, aumentando a formação da placa bacteriana e reduzindo o fluxo salivar. Jerônimo et al. (2020) concluiu que a doença periodontal tem associação significativa com a pneumonia nosocomial, já que pacientes internados com essa condição são mais propensos a desenvolverem essa infecção do que indivíduos sem periodontite.

Com a impossibilidade de autocuidados, uso dos medicamentos, hipossalivação (Rabello; Araújo; Magalhães, 2018) idade do paciente e posicionamento corporal (Güler \& Türk, 2019), consequentemente há uma redução do sistema de defesa 
inato e aumento do risco de PAVM. Portanto, é de extrema importância a criação de protocolos de higiene bucal em uma UTI. Porém, desenvolver essas novas estratégias é um desafio, uma vez que muitas das substâncias sugeridas estão associadas à resistência bacteriana (Collina et al., 2017).

Em UTIs frequentemente pacientes fazem uso de ventilação mecânica, com a presença do tubo endotraqueal há o risco de disseminação de microrganismos da orofaringe para o trato respiratório inferior, sendo um dos fatores etiológicos da PAVM. Assim é necessário a assistência para as necessidades de nutrição e higiene do paciente, especialmente cuidados com a higiene bucal para prevenir essa colonização (Lacerda Vidal et al., 2017; Zhao et al., 2020). Em concordância El-Rabbany et al. (2015) indica que cuidados de saúde bucal reduzem esse risco em pacientes de alto risco.

Com o acúmulo de placa e a colonização por patógenos, métodos para a desorganização do biofilme não só melhoram a saúde bucal e o bem-estar do paciente, mas também podem reduzir a taxa de incidência de pneumonia associada à ventilação mecânica (Haghighi et al., 2016).

A escovação possui um papel importante no combate de infecções nosocomiais em UTIs, visto que promove a remoção da placa bacteriana dos dentes e das demais estruturas da cavidade oral (Zhao et al., 2020). O biofilme oral, uma vez formado, é relativamente resistente ao controle químico, e seu controle na maioria das vezes é realizado por uma escovação feita de forma correta por profissionais capacitados, evitando causar danos as estruturas bucais e agravar o quadro de saúde (Hua et al., 2016). Além dos dentes, a superfície do dorso da língua e a mucosa oral também são consideradas importantes reservatórios de bactérias, sendo necessária a limpeza dessas regiões com escova dentária, fio dental, esponjas e gazes umedecidas com água ou clorexidina 0,12\% (Hayashida et al., 2016).

Um estudo feito por Yao et al. (2011), trouxe que a escovação dentária realizada duas vezes ao dia com água filtrada ou destilada durante um período de 7 dias reduziu significativamente a incidência cumulativa de PAVM em pacientes sob VM. A escovação dentária com água filtrada ou destilada também melhorou efetivamente a saúde e a higiene bucal desses pacientes. Em concordância Guerra et al. (2016) sugere que o uso de antimicrobianos combinados com a escovação contribui ativamente para a redução da incidência de PAVM.

Outro método amplamente citado na literatura é a utilização de clorexidina, em suas diferentes formas como enxaguatórios e géis, sozinha ou combinada com outros métodos de higiene bucal, por exemplo a escovação. É um antisséptico muito utilizado nas UTIs de todo o mundo, por possuir amplo espectro e se manter ativo nos tecidos por um período prolongado, característica conhecida como substantividade (Zhang, Tang \& Fu, 2013; Lee et al., 2019). O uso da clorexidina reduz de maneira significativa a carga patogênica do biofilme oral, além de estar interligado à redução de incidência de infecção nosocomial. Assim sugerido por Lee et al. (2019), a administração profilática dessa solução em pacientes criticamente enfermos e em UTI reduziu a ocorrência de PAVM sem impacto significativo na mortalidade.

A frequência de aplicação deve ser observada, pois suas concentrações variam de $0,12 \%, 0,2 \%$ e $2 \%$ (Güler \& Türk, 2019). Os efeitos colaterais da clorexidina observados por Rabello, Araújo e Magalhães (2018) foram irritação leve da mucosa, sabor desagradável, coloração dos dentes e disgeusia, que são mínimos e reversíveis com a suspensão do uso, apesar desses efeitos seu benefício supera suas desvantagens.

No entanto, o uso da clorexidina $0,12 \%$ não foi aprovado para aplicação na mucosa no Japão por casos de anafilaxia e, como alternativa, um estudo de Tsuda et al. (2020) verificou a aplicação de iodopovidona. Segundo ele o crescimento de todas as espécies bacterianas testadas foi inibido no grupo de intervenção $3 \mathrm{~h}$ após a higiene bucal. Em contrapartida, na pesquisa de Hayashida et al. (2016) não houve diminuição das bactérias orais com a aplicação dessa substância. Na mesma ideia, Hua et al. (2016) cita que há poucas evidências que o enxaguatório bucal com iodo seja mais eficaz que solução salina na redução da PAVM. 
Hua et al. (2016), em sua revisão com 38 ensaios clínicos randomizados, sugere que a escovação associada ao uso de um antisséptico como a clorexidina pode reduzir ainda mais a carga bacteriana ou retardar um aumento subsequente na carga. Em concordância com esse autor, Haghighi et al. (2016) concluiu em seu estudo, realizado com 100 pacientes, que o uso de solução salina $0,9 \%$, clorexidina $0,2 \%$ e escovação mecânica, combinados ou não, o grupo de intervenção apresentou melhoras significativas na saúde bucal e índice de placa.

Devido às desvantagens do uso de antibióticos, a terapia fotodinâmica (TFD) surgiu como uma técnica interessante para reduzir patógenos resistentes a antimicrobianos. O azul de metileno (MB) é o agente químico mais comum para TFD no Brasil. As vantagens em relação a outros tratamentos antimicrobianos são eficazes independente da resistência do microrganismo e seu amplo espectro de ação, atuando sobre bactérias, fungos, vírus, parasitas, etc. Essa técnica é minimamente invasiva, com baixos efeitos colaterais para o hospedeiro e pode ser considerada economicamente viável. No entanto, faltam informações sobre as relações entre os mecanismos fotoquímicos e as eficiências de inativação em diferentes microrganismos (Collina et al., 2017).

A pneumonia nosocomial pode se desenvolver através da microaspiração de bactérias patogênicas, devido ao acúmulo de secreções faríngeas próximo ao tudo endotraqueal e uma vedação imperfeita do manguito (Hayashida et al., 2016; Zhao et al 2020). Com base nisso, Klompas (2019) acredita que a drenagem dessas secreções subglóticas é uma importante estratégia para prevenção da PAVM, pois são compostas por bactérias que se multiplicam na cavidade oral, podendo causar complicações sistêmicas para os pacientes em UTIs.

Preocupações têm sido levantadas sobre falha mecânica no uso de dispositivos de sucção subglótica, podendo causar lesões na mucosa traqueal. No entanto, as mudanças no design dos tubos reduziram essas complicações, ao mesmo tempo que houve aumento nos custos desses dispositivos e tubos (Keyt, Faverio \& Restrepo, 2014).

Em um estudo realizado na unidade de terapia intensiva do Hospital Geral Ichikawa da Faculdade de Odontologia de Tóquio, com 142 pacientes sob VM, foi constatado que o nível de contaminação do manguito foi significativamente menor no grupo que utilizou o gel de hidratação oral do que o grupo padrão, e ainda o tempo necessário para uma sessão de cuidados de saúde bucal foi mais curto, sugerindo que o gel hidratante oral é eficaz na prevenção da contaminação do manguito (Takeyasu et al., 2014) e em outro estudo semelhante o uso desse gel diminuiu o nível de contaminação e invasão da faringe por bactérias e contaminantes, e a formação de biofilme no balonete (Hayashida et al., 2016).

Silvestri et al. (2016) em sua revisão sistemática para avaliar o uso da clorexidina sobre a incidência de infecção na corrente sanguínea mostrou que a higiene oral com clorexidina não reduziu a incidência de infecções sanguíneas e casos de mortalidade. Em compensação, um estudo realizado por McCue e Palmer (2019) concluiu que muitos dos veteranos em ventilação usaram essa substância por muitos anos sem a incidência de PAVM, apoiando seu uso para reduzir os dias de administração antibiótica causando menos efeitos colaterais.

Em um ensaio clínico randomizado, Bellissimo-Rodrigues et al. (2014) concluíram que os cuidados odontológicos foram seguros e eficazes para prevenir infecções do trato respiratório inferior em pacientes gravemente enfermos de UTI. Em concordância Viana et al. (2013) realizou um ensaio clínico não controlado com um conjunto de intervenções, no Rio de Janeiro, e avaliou através de um conjunto de ferramentas preventivas que a taxa de PAVM reduziu de 18,6\% para 11,8\% após essas intervenções.

De acordo com a revisão de escopo de Alecrim et al. (2019), a aplicação de medidas baseadas em evidências científicas se provou ser eficaz quando realizado em conjunto, impactando na redução da incidência de pneumonia associada à ventilação mecânica. 


\section{Conclusão}

Conclui-se que atualmente não existe um protocolo específico de higiene bucal para prevenção da Pneumonia Nosocomial. De acordo com o presente estudo de revisão, o uso da clorexidina associado a uma escovação eficiente e aspiração de secreções acumuladas próximas ao tubo endotraqueal podem apresentar redução na incidência de PAVM.

Em relação ao uso do iodo povidona, géis de hidratação oral e da terapia fotodinâmica, mais estudos são necessários para seu uso apesar de serem considerados alternativas promissoras para prevenção dessas infecções nosocomiais. Por fim, destaca-se a importância do treinamento e capacitações dos profissionais responsáveis pelas UTIs, principalmente por cirurgiões dentistas habilitados em odontologia hospitalar.

Ainda são necessários mais estudos experimentais com maiores números amostrais para ser desenvolvido um protocolo específico para a redução da pneumonia nosocomial, não somente elaborado pela classe odontológica, mas também por toda equipe multidisciplinar.

\section{Referências}

Alecrim, R. X., Taminato, M., Belasco, A., Longo, M. C. B., Kusahara, D. M. \& Fram, D. (2019). Strategies for preventing ventilator-associated pneumonia: an integrative review. Rev Bras Enferm.72(2):521-530. 10.1590/0034-7167-2018-0473.

Bao, L., Zhang, C., Dong, J., Zhao, L., Li, Y. \& Sun, J. (2020). Oral Microbiome and SARSCoV-2: Beware of Lung Co-infection. Front Microbiol. 31;11:1840. 10.3389/fmicb.2020.01840.

Bellissimo-Rodrigues, W. T., Menegueti, M. G., Gaspar, G. G., Nicolini, E. A., Auxiliadora-Martins, M., Basile-Filho, A., Martinez, R. \& BellissimoRodrigues, F. (2014). Effectiveness of a dental care intervention in the prevention of lower respiratory tract nosocomial infections among intensive care patients: a randomized clinical trial. Infect Control Hosp Epidemiol. 35(11):1342-8. 10.1086/678427.

CDC. Centre For Disease Prevention and Control. (2020). Interim guidance for environmental cleaning in non-healthcare facilities exposed to SARS-CoV-2. Disponível em: https://www.ecdc.europa.eu/en/publications-data/interim-guidance-environmental-cleaning-non-healthcare-facilities-exposed-2019.

CFO. Recomendações AMIB/CFO para atendimento odontológico COVID- 19 em UTI: Comitê de Odontologia AMIB/CFO de enfrentamento ao COVID-19. (2021) Departamento de Odontologia AMIB, 4ed. Disponível em: https://website.cfo.org.br/wp-content/uploads/2021/03/Recomendacoes-AMIB-CFO-paraenfrentamento-da-covid-19-na-Odontologia.pdf.

CFO. Resolução CFO-162/2015. (2015). Reconhece o exercício da Odontologia Hospitalar pelo cirurgião-dentista. Rio de Janeiro, R.J. Disponível em: https://website.cfo.org.br/wp-content/uploads/2015/12/ResolucaoCFO-162-15.pdf

Collina G. A. da, Tempestini-Horliana, A. C. R., Silva, D. F. T. da, Longo, P. L., Makabe, M. L. F. \& Pavani, C. (2017). Oral hygiene in intensive care unit patients with photodynamic therapy: study protocol for randomised controlled trial. Trials. 18(1):385. 10.1186/s13063-017-2133-y.

El-Rabbany, M., Zaghlol, N., Bhandari, M. \& Azarpazhooh, A. (2015). Prophylactic oral health procedures to prevent hospital-acquired and ventilatorassociated pneumonia: a systematic review. Int J Nurs Stud. 52(1):452-64. 10.1016/j.ijnurstu.2014.07.010.

Guerra, F., De Martino, F., Capocci, M., Rinaldo, F., Mannocci, A., De Biase, A., Ottolenghi, L. \& La Torre, G. VAP and oral hygiene.A systematic review. Clin Ter. 167(6):198-205. 10.7417/CT.2016.1973.

Güler E. K. \& Türk G. (2019) Oral Chlorhexidine Against Ventilator-Associated Pneumonia and Microbial Colonization in Intensive Care Patients. West J Nurs Res. 41(6):901-919. 10.1177/0193945918781531.

Haghighi, A., Shafipour,V., Bagheri-Nesami, M., Gholipour Baradari, A. \& Yazdani Charati, J. (2017)The impact of oral care on oral health status and prevention of ventilator-associated pneumonia in critically ill patients. Aust Crit Care. 30(2):69-73. 10.1016/j.aucc.2016.07.002.

Hayashida, S., Funahara, M., Sekino, M., Yamaguchi, N., Kosai, K., Yanamoto, S., Yanagihara, K. \& Umeda, M. (2016). The effect of tooth brushing, irrigation, and topical tetracycline administration on the reduction of oral bacteria in mechanically ventilated patients: a preliminary study. BMC Oral Health. 16(1):67. 10.1186/s12903-016-0224-x.

Hua, F., Xie, H., Worthington, H. V., Furness, S., Zhang, Q. \& Li, C. (2016). Oral hygiene care for critically ill patients to prevent ventilator-associated pneumonia. Cochrane Database Syst Rev. 10(10):CD008367. 10.1002/14651858.CD008367.pub3.

Jerônimo, L. S., Abreu, L. G., Cunha, F. A. \& Lima, R. P. E. (2020). Association Between Periodontitis and Nosocomial Pneumonia: A Systematic Review and Meta-analysis of Observational Studies. Oral Health Prev Dent. 18(1):11-17. 10.3290/j.ohpd.a44114.

Keyt H., Faverio, P. \& Restrepo, M. I. (2014). Prevention of ventilator-associated pneumonia in the intensive care unit: a review of the clinically relevant recent advancements. Indian J Med Res.139(6):814-21. Recuperado de: https://pubmed.ncbi.nlm.nih.gov/25109715/.

Klompas, M. (2019). Prevention of Intensive Care Unit-Acquired Pneumonia. Semin Respir Crit Care Med. 40(4):548-557. 10.1055/s-0039-1695783. 
Lacerda Vidal, C. F., Vidal, A. K., Monteiro, J. G. Jr, Cavalcanti, A., Henriques, A. P. C., Oliveira, M., Godoy, M., [...] \& Lacerda, H.R. Impact of oral hygiene involving toothbrushing versus chlorhexidine in the prevention of ventilator-associated pneumonia: a randomized study. BMC Infect Dis. $17(1): 112$. $10.1186 / \mathrm{s} 12879-017-2188-0$

Lee, S., Lighvan, N. L., McCredie, V., Pechlivanoglou, P., Krahn, M., Quiñonez, C. \& Azarpazhooh, A. (2019). Chlorhexidine-Related Mortality Rate in Critically Ill Subjects in Intensive Care Units: A Systematic Review and Meta-Analysis. Respir Care. 64(3):337-349. 10.4187/respcare.06434.

McCue, M. K. \& Palmer, G. A. (2019). Use of Chlorhexidine to Prevent Ventilator-Associated Pneumonia in a Long-term Care Setting: A Retrospective Medical Record Review. J Nurs Care Qual. 34(3):263-268. 10.1097/NCQ.0000000000000367.

Mendes, K. S., Silveira, R. S., Pereira, C. S., Galvão, C. M. (2008). Revisão integrativa: método de pesquisa para a incorporação de evidências na saúde e na enfermagem. Texto contexto - enferm. 17(4):758-764. Available from: http://www.scielo.br/scielo.php?script=sci_arttext\&pid=S0104-07072008000400018

Rabello, F., Araújo, V. E. \& Magalhães, S. (2018). Effectiveness of oral chlorhexidine for the prevention of nosocomial pneumonia and ventilator-associated pneumonia in intensive care units: Overview of systematic reviews. Int J Dent Hyg. 16(4):441-449. 10.1111/idh.12336.

Santi, S., S. \& Santos, R. B. (2016). A prevalência da pneumonia nosocomial e sua relação com a doença periodontal: revisão de literatura. Revista Da Faculdade De Odontologia - UPF, 21(2). https://doi.org/10.5335/rfo.v21i2.5799

Santos, O. M. dos, Carvalho, L. de S. L., Pita, R. T. S., Pereira, L. S., Almeida, S. P. de, Ramos, H. M. P., \& Toledo, M. M. (2020). Fake News na Pandemia da Covid-19: um desserviço à sociedade brasileira. Revista Cenas Educacionais, 3(e9300),1-16. https://revistas.uneb.br/index.php/cenaseducacionais/article/view/9300

Silvestri, L., Weir, W. I., Gregori, D., Taylor, N., Zandstra, D. F., van Saene, J. J. M. \& van Saene, H. K. F. (2017). Impact of Oral Chlorhexidine on Bloodstream Infection in Critically Ill Patients: Systematic Review and Meta-Analysis of Randomized Controlled Trials. J Cardiothorac Vasc Anesth. 31(6):2236-2244. 10.1053/j.jvca.2016.11.005.

Takeyasu, Y., Yamane, G. Y., Tonogi, M., Watanabe, Y., Nishikubo, S., Serita, R. \& Imura, K. (2014). Ventilator-associated pneumonia risk decreased by use of oral moisture gel in oral health care. Bull Tokyo Dent Coll. 55(2):95-102. 10.2209/tdcpublication.55.95.

Tsuda, S., Soutome, S., Hayashida, S., Funahara, M., Yanamoto, S. \& Umeda, M. (2020). Topical povidone iodine inhibits bacterial growth in the oral cavity of patients on mechanical ventilation: a randomized controlled study. BMC Oral Health. 20(1):62. 10.1186/s12903-020-1043-7.

Viana, W. N., Bragazzi, C., Castro J. E. C. de, Alves, M. B. \& Rocco, J. R. (2013). Ventilator-associated pneumonia prevention by education and two combined bedside strategies. Int J Qual Health Care. 25(3):308-13. 10.1093/intqhe/mzt025.

WHO. World Health Organization. (2020). Clinical management of severe acute respiratory infection when novel coronavirus (2019-nCoV) infection is suspected: interim guidance. https://apps.who.int/iris/handle/10665/330893

Yao, L. Y., Chang, C. K., Maa, S. H., Wang, C. \& Chen, C. C. (2011). Brushing teeth with purified water to reduce ventilator-associated pneumonia. J Nurs Res. 19(4):289-97. 10.1097/JNR.0b013e318236d05f.

Zhang, T. T., Tang, S. S. \& Fu, L. J. (2014). The effectiveness of different concentrations of chlorhexidine for prevention of ventilator-associated pneumonia: a meta-analysis. J Clin Nurs. 23(11-12):1461-75. 10.1111/jocn.12312.

Zhao, T., Wu, X., Zhang, Q., Li, C., Worthington, H. V. \& Hua F. (2020). Oral hygiene care for critically ill patients to prevent ventilator-associated pneumonia. Cochrane Database Syst Rev.12:CD008367. 10.1002/14651858.CD008367.pub4. 